\title{
OSCILLATIONS OF SEMI-ENCLOSED WATER BODY INDUCED BY HURRICANES
}

\author{
Yuan-Hung Paul Tan ${ }^{1}$ and Jiin-Jen Lee ${ }^{1}$
}

\begin{abstract}
The primary focus of this research is to study the oscillations of semi-enclosed water body induced by hurricanes. The physical mechanisms of the wind-induced oscillation (storm surge) in a semi-enclosed water body are analyzed by the depth-averaged, non-linear shallow-water equations. The numerical model using the finite-volume method (FVM) to solve the depth-averaged, non-linear shallow-water equations is developed and the present model is verified by the intensive field data reported by IPET. The present model is further applied to the investigation of the oscillations (storm surges) in Lake Pontchartrain induced by the winds generated by four synthetic hurricanes within the time-span of 00:00 UTC August 29 to 00:00 UTC August 30, 2005: 1.Hurricane Katrina tracking on its original route, 2.Hurricane Katrina tracking $36 \mathrm{~km}$ west of its original route, 3.Hurricane Katrina tracking $72 \mathrm{~km}$ west of its original route, and 4.Hurricane Katrina tracking on its original route with reduced forward speeds. The major application of the present model is to assist the design of the water-front structure surrounding the semi-enclosed water body that has been influenced by the oscillations induced by hurricanes. The numerical simulations generated by the present model can help the planners to determine a better strategy of the hurricane protection systems surrounding the communities of the semi-enclosed water body.
\end{abstract}

Keywords: oscillation; hurricane; depth-averaged, non-linear shallow-water equations; finite-volume method; riskbased design \& analysis

\section{INTRODUCTION}

The hurricane-induced oscillation (storm surge) of bays, harbors, and lakes can have a direct effect on shipping and design of flood protection system for beach and coastal communities. Inundation in both estuarine tidal flats and riverine flood planes due to the storm surge not only causes casualties and property damages but also affects the deposition and erosion of sediments in the coastal areas. Predictions of flooding due to storm surge, dam breaching, or levee overtopping are crucial for planning of emergency response.

Hurricane Katrina was formed over the Bahamas on August 23, 2005, and crossed southern Florida as a moderate Category 1 hurricane. It then strengthened rapidly in the Gulf of Mexico and became one of the strongest hurricanes on record while at sea. The hurricane weakened before making its second and third landfalls as a Category 3 storm on the morning of August 29 in southern Louisiana and at the Louisiana/Mississippi state line, respectively. Hurricane Katrina was the costliest and one of the five deadliest hurricanes in the history of the United States.

Lake Pontchartrain is a brackish lake located in southeastern Louisiana. It is roughly oval in shape with an average depth of 12 to 14 feet (about 4 meters), about 40 miles (64 km) wide and 24 miles (39 $\mathrm{km}$ ) from south to north. The south shore forms the northern boundary of the city of New Orleans. Storm surge can build up in Lake Pontchartrain during hurricanes. Wind drives water into the lake from the Gulf of Mexico as a hurricane approaches from the south, and water can spill into New Orleans from the lake.

Although Katrina weakened to a Category 3 before making landfall on August 29, some canals began leaking at 8 a.m. CDT (Chalmette, Louisiana) and some levees/canals, designed to withstand Category 3 storms, suffered multiple breaks the following day, flooding $80 \%$ of New Orleans. The walls of the Inner Harbor Navigation Canal (IHNC) were breached by storm surge via the Mississippi River Gulf Outlet (MRGO), while the $17^{\text {th }}$ Street Canal and the London Avenue Canal experienced catastrophic breaches, even though water levels never topped their flood walls. Aerial photography suggests that 25 billion gallons (95 billion liters) of water covered New Orleans as of September 2, which equals about $2 \%$ of Lake Pontchartrain's volume.

The major objective of this research is to investigate the oscillations of semi-enclosed water body induced by hurricanes. The depth-averaged, non-linear shallow-water equations are used to analyze storm surge (oscillation) in a semi-enclosed lake induced by a hurricane. Because conservation of mass and momentum is crucial in simulating the oscillations in a semi-enclosed lake induced by strong winds, the finite-volume method (FVM) is used to solve the depth-averaged, non-linear shallow-water equations in this study. The extensive field data gathered for the region of Lake Pontchartrain is used for the comparison with the computational results from the present model. The essential-

\footnotetext{
${ }^{1}$ Sonny Astani Department of Civil and Environmental Engineering, University of Southern California, $3620 \mathrm{~S}$. Vermont Avenue, Suite 210, Los Angeles, California, 90089, U.S.A.
} 
meteorological data to re-generate Hurricane Katrina and the field-observatory and the instrumentrecorded water surface elevations (WSE's) at Lake Pontchartrain are obtained from the "Performance Evaluation of the New Orleans and Southern Louisiana Hurricane Protection System" report dated June 1, 2006 made by the Interagency Performance Evaluation Task Force (IPET). After the verification of the computational results is complete, the present model is further applied to simulate the oscillation scenarios of water surface in Lake Pontchartrain induced by Hurricane Katrina and some synthetic hurricanes.

\section{GOVERNING EQUATIONS}

For the present study, the depth-average shallow-water equations are used to analyze the physical mechanisms of the wind-induced oscillations in semi-enclosed water bodies:

$$
\begin{aligned}
& \frac{\partial \eta}{\partial t}+\frac{\partial}{\partial x}[(h+\eta) u]+\frac{\partial}{\partial y}[(h+\eta) v]=0 \\
& \frac{\partial u}{\partial t}+u \frac{\partial u}{\partial x}+v \frac{\partial u}{\partial y}-f v= \\
& -g \frac{\partial \eta}{\partial x}-\frac{1}{\rho} \frac{\partial p_{a}(r)}{\partial x}+v_{T}\left(\frac{\partial^{2} u}{\partial x^{2}}+\frac{\partial^{2} u}{\partial y^{2}}\right)+\frac{\left(\tau_{x}^{\eta}-\tau_{x}^{-h}\right)}{\rho(h+\eta)} \\
& \frac{\partial v}{\partial t}+u \frac{\partial v}{\partial x}+v \frac{\partial v}{\partial y}+f u= \\
& -g \frac{\partial \eta}{\partial y}-\frac{1}{\rho} \frac{\partial p_{a}(r)}{\partial y}+v_{T}\left(\frac{\partial^{2} v}{\partial x^{2}}+\frac{\partial^{2} v}{\partial y^{2}}\right)+\frac{\left(\tau_{y}^{\eta}-\tau_{y}^{-h}\right)}{\rho(h+\eta)}
\end{aligned}
$$

in the Cartesian Coordinate system, where $\eta=$ water surface elevation above mean water surface; $h=$ water depth below mean water surface. $(u, v)$ are the depth-averaged horizontal velocity components; $\rho$ =water density; $p_{a}(r)=$ atmospheric pressure; $v_{T}=$ eddy viscosity; $\left(\tau_{x}^{\eta}, \tau_{y}^{\eta}\right)$ and $\left(\tau_{x}^{-h}, \tau_{y}^{-h}\right)=$ the surface wind stress and the bottom drag components, respectively. $f$ is the Coriolis parameter ( $f=2 \Omega \sin (\theta)$, where $\Omega$ is the angular velocity of the earth and $\theta$ is the latitude); and $g$ is the gravitational acceleration.

\section{MODEL VERIFICATION}

The present model is used to study the oscillation in Lake Pontchartrain induced by wind generated by Hurricane Katrina. The time-period in the verification processes for the present model is from 12:00 am UTC August 29, 2005 to 12:00 am UTC August 30, 2005.

The wind field inducing the oscillations in Lake Pontchartrain is exclusively caused by Hurricane Katrina. The meteorological data to simulate Hurricane Katrina between 12:00 am UTC August 29, 2005 and 12:00 am UTC August 30, 2005 is adopted from the Interagency Performance Evaluation Task Force (IPET) report.

According to the Volume V of the IPET report, titled The Performance-Levees and floodwalls, there are several breaches of the floodwalls and levees on the $17^{\text {th }}$ Street Canal, the London Avenue Canal, and the Inner Harbor Navigation Canal (IHNC) during the invasion of Hurricane Katrina. In order to accommodate the phenomena of both breaches and/or overtopping of floodwalls and levees along Lake Pontchartrain, water flows out of the lake through the entrances of the $17^{\text {th }}$ Street Canal, the London Avenue Canal, and the Inner Harbor Navigation Canal (IHNC) at the $15^{\text {th }}$ hour (or 03:00 pm UTC) of the numerical simulations performed for the model verification.

The field measurement data at the $17^{\text {th }}$ Street Canal, the Orleans Avenue Canal, the London Avenue Canal, the Inner Harbor Navigation Canal (IHNC)-Lakefront Airport, Midlake, Bayou Labranch, Pass Manchac, and Little Irish Bayou reported in the Interagency Performance Evaluation Task Force (IPET) report are compared with the hydrographs due to Hurricane Katrina obtained from the present model for the model verification. The aerial photo showing these eight (8) selected 
locations is presented in Figure 1. In this article, the three (3) representative results of comparison (the $17^{\text {th }}$ Street Canal, Midlake, and Little Irish Bayou) will be presented in the following paragraphs.

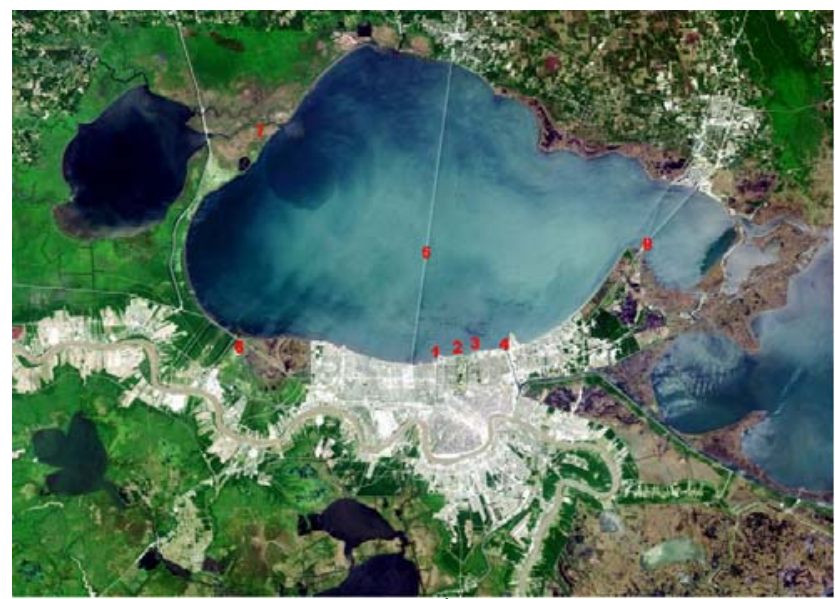

Figure 1. Aerial Photo Showing the $17^{\text {th }}$ Street Canal (1), the Orleans Avenue Canal (2), the London Avenue Canal (3), IHNC (4), Midlake (5), Bayou Labranch (6), Pass Manchac (7), and Little Irish Bayou (8).

The computed hydrograph (solid black line) obtained from the present model and the observed hydrograph (red line with star symbol) at the entrance of the $17^{\text {th }}$ Street Canal are presented in Figure 2. From Figure 2, it is seen that the present model-computed time when the peak water surface elevation (WSE, so called water level in the IPET report) happens is almost identical to the recorded time at which the maximum water level happened at the entrance of the $17^{\text {th }}$ Street Canal site. The difference of the maximum water level (water surface elevation, WSE) is approximately 0.01 meter (3.3020 m versus $3.2918 \mathrm{~m}$ ). It shows that the present model does predict the general trend of the rise and fall of the water level at the entrance of the $17^{\text {th }}$ Street Canal site.

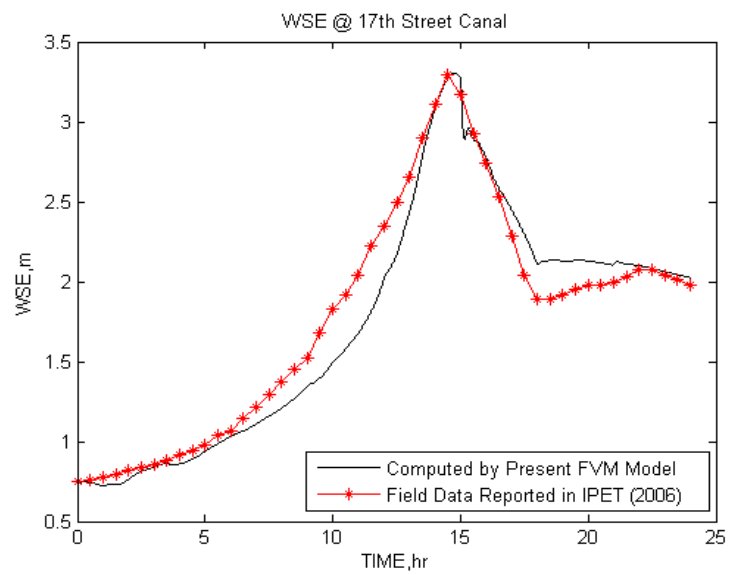

Figure 2. Computed Hydrograph versus Observed Hydrograph, $17^{\text {th }}$ Street Canal

The computed hydrograph (solid black line) obtained from the present model and the observed hydrograph (light blue line with cross symbol) for the Midlake are presented in Figure 3. According to the IPET report, the Midlake gage stopped operating in the middle of the storm; hence, the comparison of the computed and the observed hydrographs should focus on the times at which the Midlake gage data is still available between 12:00 am August 29 and 12:00 am August 30 2005. From Figure 3, it shows that the present model does predict the general trend of the rise of the water level prior to the stop-recording of the Midlake gage when the hydrograph due to Hurricane Katrina is compared with the observed hydrograph at the Midlake site. 


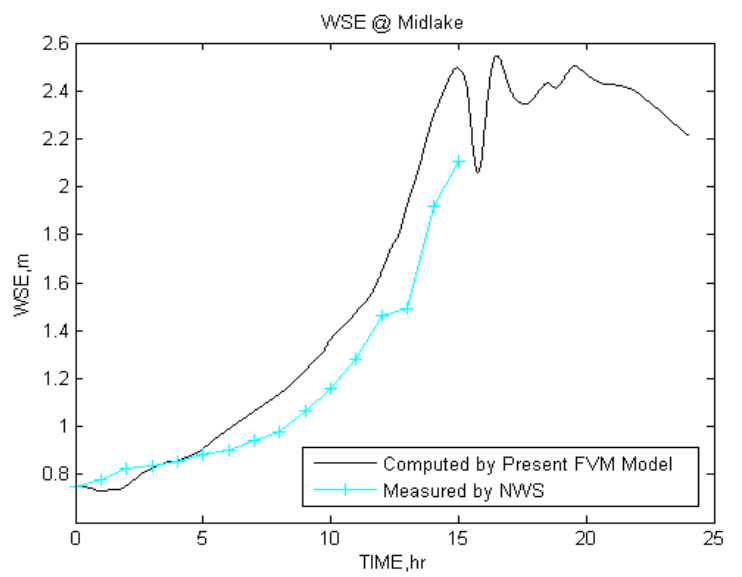

Figure 3. Computed Hydrograph versus Observed Hydrograph, Midlake

The computed hydrograph (solid black line) obtained from the present model and the observed hydrograph (green line with circle symbol) for Little Irish Bayou are presented in Figure 4. According to the IPET report, the Little Irish Bayou gage failed before high water levels were reached; hence, the comparison of the computed and the observed hydrographs should focus on the times at which the Little Irish Bayou gage data is available. From Figure 4, it is seen that the general trend of the rise and fall of the water level predicted by the present model is not very close to the general trend of the rise and fall of the water level because the present model does not include the intruding water from the Gulf of Mexico through the swamps along the east shore of Lake Pontchartrain. In detail, the present model can accurately predict the general trend of the rise of the water level between 10:00 am and 14:00 pm UTC August 29, 2005 as it is seen from Figure 4; however, the obvious differences between the computed and observed hydrographs can be seen when the computed hydrograph obtained from the present model is compared with the observed hydrograph between 12:00 and 09:00 am at Little Irish Bayou site. Based on the observational information provided in the IPET report, the low-land areas between Lake Pontchartrain and the Gulf of Mexico have been inundated by the storm surges induced by Hurricane Katrina before the start (12:00 am UTC August 29, 2005) of the current computational simulation. In other words, the storm surges from the Gulf of Mexico had been affecting the rise and fall of the water level at the east part of Lake Pontchartrain, at which the Little Irish Bayou gage is located, since Hurricane Katrina was approaching to the Southeast Louisiana. Based on the data and simulation results, the present model does predict the general trend of the water level at Little Irish Bayou site.

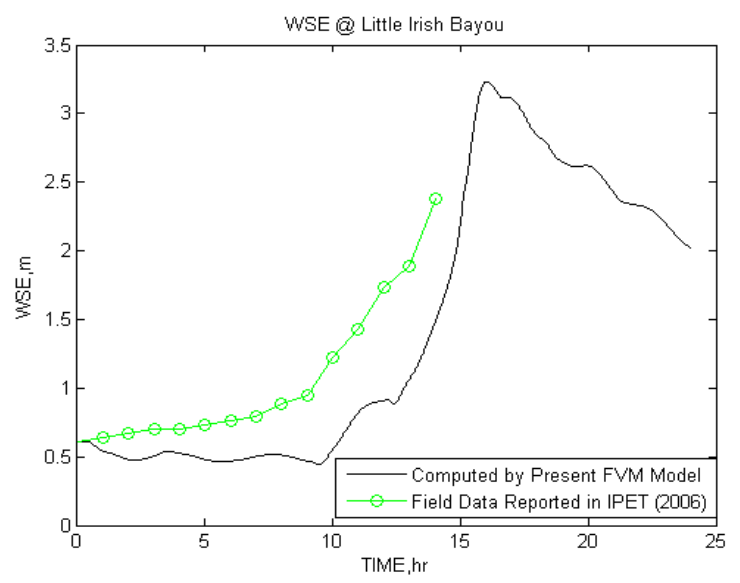

Figure 4. Computed Hydrograph versus Observed Hydrograph, Little Irish Bayou

Because the general trends of water levels either are accurately predicted at the $17^{\text {th }}$ Street Canal, the Orleans Avenue Canal (not shown), the London Avenue Canal (not shown), the IHNC-Lakefront Airport (not shown), the Midlake, and the Pass Manchac-Manchac (not shown) sites or are reasonably 
predicted at the Bayou La Branche (not shown), Pass Manchac-Turtle Cove (not shown), and the Little Irish Bayou sites by the present model when the hydrographs due to Hurricane Katrina are compared with the constructed/observed hydrographs at these sites, it is reasonable to claim that the present model for solving the depth-averaged, non-linear shallow water equations provides a modeling tool to study the oscillations of semi-enclosed water body induced by hurricanes. Furthermore, the present model will be used in several detailed studies of the oscillations in Lake Pontchartrain induced by winds generated through Hurricane Katrina and other synthetic hurricanes.

\section{MODEL APPLICATIONS}

After the validity of the present model for solving the depth-averaged, non-linear shallow water equations has been affirmed, the present model is applied to study the wind-induced oscillations in Lake Pontchartrain generated by four (4) different synthetic hurricanes: 1. Original Hurricane Katrina (Route 1 in Figure 5), 2. Hurricane Katrina passes above east part of New Orleans, Louisiana (Route 2 in Figure 5), 3. Hurricane Katrina passes through the regions along the west shore of Lake Pontchartrain, including Lake Maurepas (Route 3 in Figure 5), and 4. A synthetic hurricane travels the same route as Hurricane Katrina with reduced forward speeds (Route 1 in Figure 5). In order to study the oscillation phenomena in Lake Pontchartrain induced by these four (4) hurricanes, the breaches and/or overtopping of floodwalls and levees along Lake Pontchartrain will not be accommodated into the numerical simulations performed by the present model, i.e. assuming that the canal walls do not breach. Therefore, the water can not flow out of the lake through the entrances of the canals connecting to the lake during the entire 24-hours period of the numerical simulations for the oscillations of Lake Pontchartrain induced by these four (4) synthetic hurricanes.

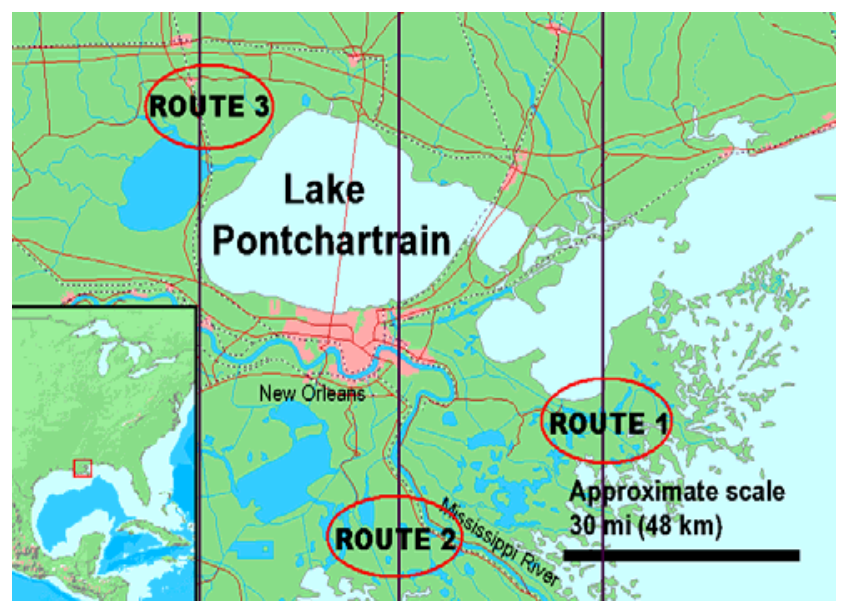

Figure 5. Map Showing Different Routes of Hurricanes

In order to examine the oscillations in Lake Pontchartrain induced by wind generated through these hurricanes in detail, including original Hurricane Katrina, two cross sections (South-North (S-N) and West-East (W-E)) of Lake Pontchartrain are drawn. The map showing the locations of both cross sections of Lake Pontchartrain is presented in Figure 6. The computed hydrographs of both S-N and W-E cross sections and the computed contour maps of the entire Lake Pontchartrain are used to present the oscillation phenomena in Lake Pontchartrain induced by winds generated through these four (4) hurricanes. The discussions of these hydrographs and contours maps showing the wind-induced oscillations in Lake Pontchartrain generated by the present model are presented in the following subsections. 


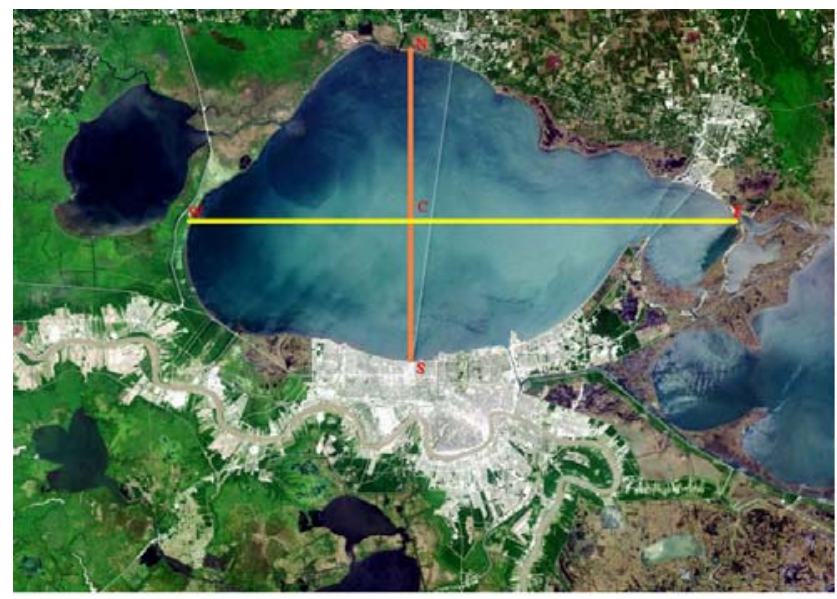

Figure 6. Approximate Locations of N-S and W-E cross-sections

\section{Original Hurricane Katrina (Route 1)}

The computed hydrograph (solid black line) obtained from the present model for the $17^{\text {th }}$ Street Canal is presented in Figure 7. The contour map showing the computed water surface elevation (WSE) for the entire Lake Pontchartrain at the $15^{\text {th }}$ hour is presented in Figure 8.

From Figure 7, it is seen that the peak water surface elevation induced by the Route 1-traveling Hurricane Katrina is equal to the peak water surface level induced by the original Hurricane Katrina at the $17^{\text {th }}$ Street Canal site after comparing the computed hydrograph made under the wind generated by the Route 1-traveling Hurricane Katrina without breach and/or overtopping of floodwalls and levees along Lake Pontchartrain with the one made under the wind generated by the original Hurricane Katrina with the scenario of the leakage from the lake through the breaches and/or overtopping of floodwalls and levees along Lake Pontchatrain (see the solid red line in Figure 7). However, it can be seen that the residual water surface elevations for the Route 1-traveling Hurricane Katrina without breach and/or overtopping of floodwalls and levees along Lake Pontchartrain are much higher than the ones for the original Hurricane Katrina with the scenario of the leakage from the lake through the breaches and/or overtopping of floodwalls and levees along Lake Pontchatrain after the $15^{\text {th }}$ hour of the numerical simulations. Hence, this is an evidential proof that the tremendous amount water leaking from Lake Pontchartrain through the breaches and/or overtopping of floodwalls and levees can bring a devastating damage to the communities along the lake.

Furthermore, the moving direction of the storm surge changes from the west direction to the east direction in a counterclockwise-turning pattern within the first 16-hours period (12:00 am to 04:00 pm UTC August 29, 2005) of the numerical simulations (the sloshing motion changes $180^{\circ}$ in 16 hours).

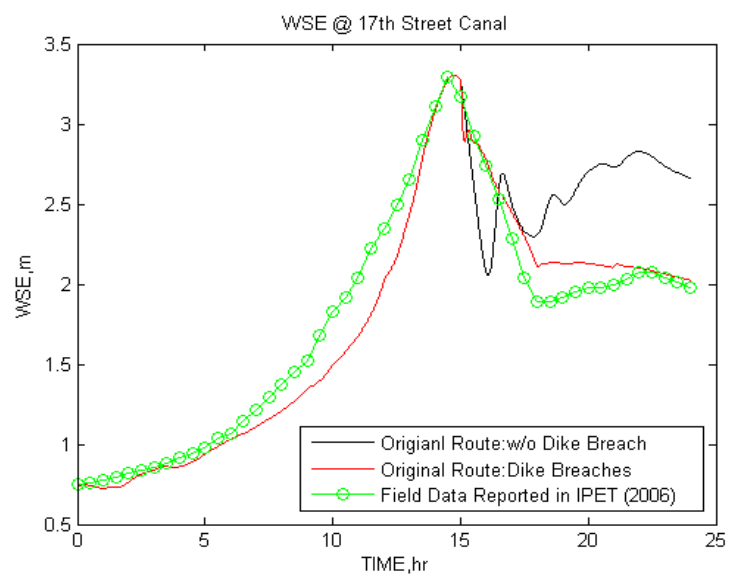

Figure 7. Computed Hydrograph, $17^{\text {th }}$ Street Canal 


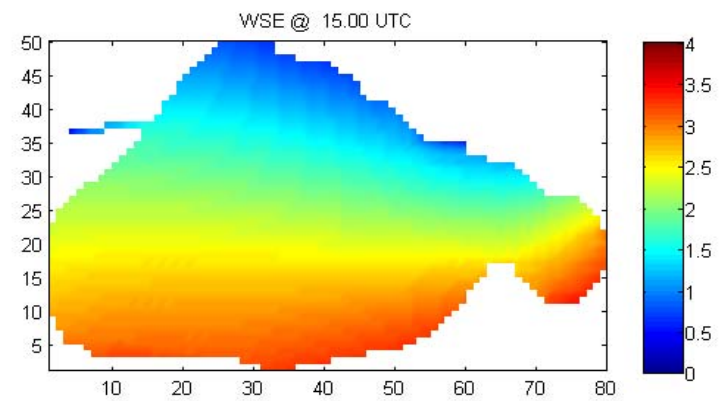

Figure 8. Contours of WSE at 03:00 pm (UTC) August 29, 2005

The computed hydrographs of the water surface elevation (WSE) showing on S-N and W-E crosssections of Lake Pontchartrain induced by the wind generated through the Route 1-traveling Hurricane Katrina are presented in Figures 9 and 10, respectively. It is seen from Figures 9 and 10 that the windinduced oscillations in Lake Pontchartrain are the evident phenomena as Hurricane Katrina progressed over the Southeast Louisiana region (Route 1 in Figure 5).

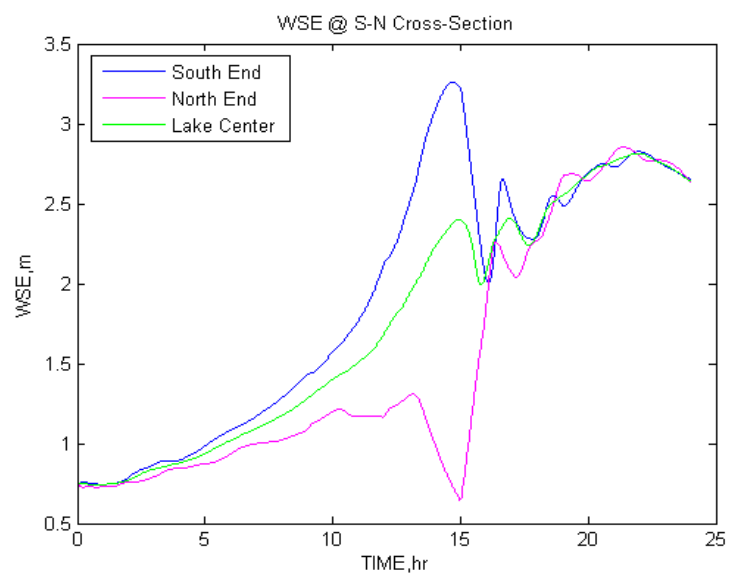

Figure 9. Hydrographs of the S-N cross-section

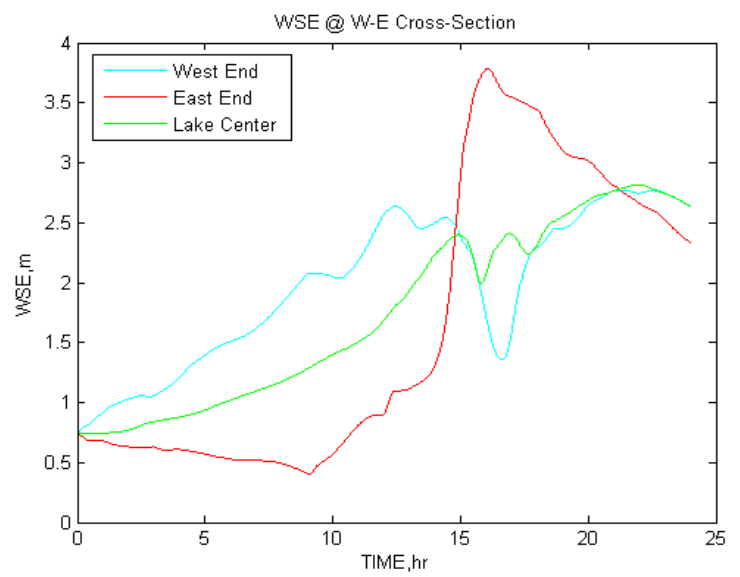

Figure 10. Hydrographs of the W-E cross-section 


\section{Hurricane Katrina Traveling Along Route 2}

The computed hydrograph (solid black line) obtained from the present model for the $17^{\text {th }}$ Street Canal is presented in Figure 11. The contour map showing the computed water surface elevation (WSE) for the entire Lake Pontchartrain at the $15^{\text {th }}$ hour is presented in Figure 12.

From Figure 11, it is seen that the peak water surface elevation (WSE) computed by the present model is approximately $3.8621 \mathrm{~m}$ at the $17^{\text {th }}$ Street Canal site. It is also seen that the peak water surface elevation induced by the Route 2-traveling Hurricane Katrina is much higher than the peak water surface level induced by the Route 1-traveling Hurricane Katrina at the $17^{\text {th }}$ Street Canal site (3.8621 m versus $3.3020 \mathrm{~m}$ ) after comparing the computed hydrograph made under the wind generated by the Route 2-traveling Hurricane Katrina with the one made under the wind generated by the Route 1-traveling Hurricane Katrina (see the solid red line in Figure 11). Therefore, it can be claimed that this significant difference in water surface elevation is caused by a hurricane passing over Lake Pontchartrain with another route although the strength (pressure and wind speed) of this synthetic hurricane is identical to the original Hurricane Katrina.

Furthermore, the moving direction of the storm surge changes from the west direction to the east direction in a counterclockwise-turning pattern within the first 16-hours period (12:00 am to 04:00 pm UTC August 29, 2005) of the numerical simulations (the sloshing motion changes $180^{\circ}$ in 16 hours).

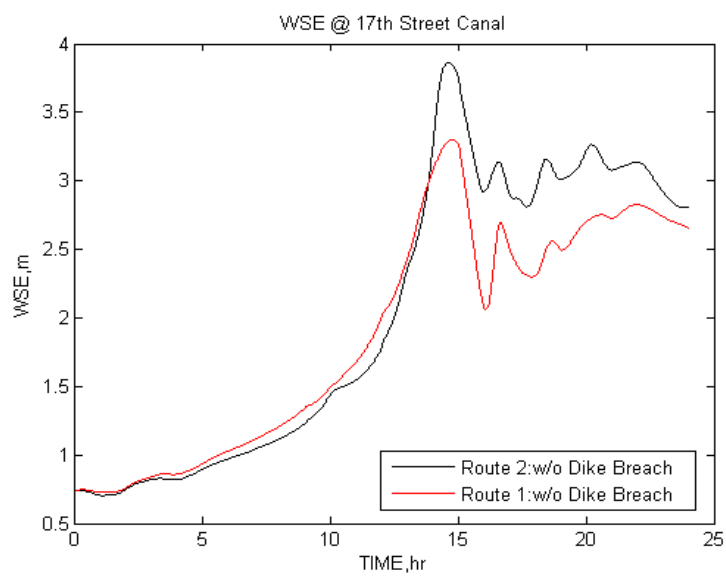

Figure 11. Computed Hydrograph, $17^{\text {th }}$ Street Canal

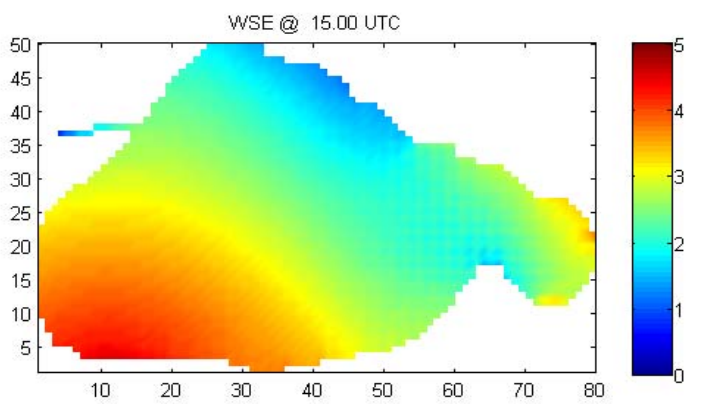

Figure 12. Contours of WSE at 03:00 pm (UTC) August 29, 2005

The computed hydrographs of the water surface elevation (WSE) showing on S-N and W-E crosssections of Lake Pontchartrain induced by the wind generated through the Route 2-traveling Hurricane Katrina are presented in Figures 13 and 14, respectively. It is seen from Figures 13 and 14 that the wind-induced oscillations in Lake Pontchartrain are the evident phenomena as Hurricane Katrina progressed over the east part of New Orleans, Louisiana (Route 2 in Figure 5). 


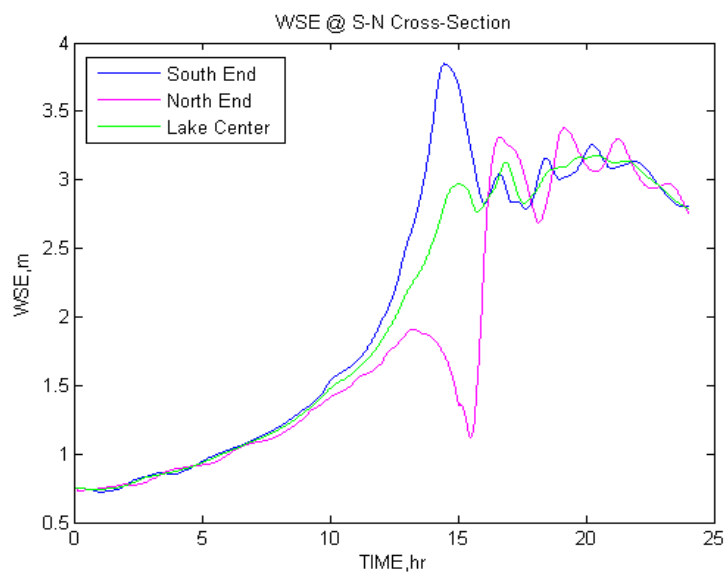

Figure 13. Hydrographs of the S-N cross-section

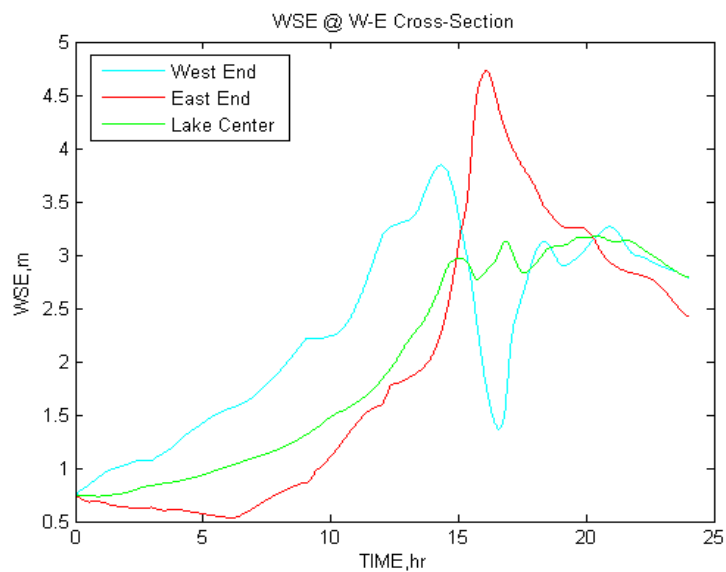

Figure 14. Hydrographs of the W-E cross-section

\section{Hurricane Katrina Traveling Along Route 3}

The computed hydrograph (solid black line) obtained from the present model for the $17^{\text {th }}$ Street Canal is presented in Figure 15. The contour map showing the computed water surface elevation (WSE) for the entire Lake Pontchartrain at the $15^{\text {th }}$ hour is presented in Figure 16.

From Figure 15, it is seen that the peak water surface elevation (WSE) computed by the present model is approximately $3.1089 \mathrm{~m}$ at the $17^{\text {th }}$ Street Canal site. It is also seen that an abrupt fall and rise of water level $\left(2.7282 \mathrm{~m}\right.$ ) within 2 hours is computed by the present model at the $17^{\text {th }}$ Street Canal site; in other words, this sudden change of water surface elevation (WSE) can caused a severe damage to the ships mooring around the entrance of the $17^{\text {th }}$ Street Canal. Furthermore, it is seen that the peak water surface elevation induced by the Route 3-traveling Hurricane Katrina is lower than the peak water surface level induced by the Route 1-traveling Hurricane Katrina at the $17^{\text {th }}$ Street Canal site (3.1089 m versus $3.3020 \mathrm{~m}$ ) after comparing the computed hydrograph made under the wind generated by the Route 3-traveling Hurricane Katrina with the one made under the wind generated by the Route 1-traveling Hurricane Katrina (see the solid red line in Figure 15). The general trend of the fall and rise of water level induced by the wind generated by the Route 3-traveling Hurricane Katrina is entirely different from the general trend of the rise and fall of water level induced by the wind generated by the Route 1-traveling Hurricane Katrina. Therefore, it can be claimed that these apparent differences in water surface elevation is caused by a hurricane passing over Lake Pontchartrain with another route although the strength (pressure and wind speed) of this synthetic hurricane is identical to the original Hurricane Katrina.

Furthermore, the moving direction of the storm surge changes from the west direction to the east direction in a clockwise-turning pattern within the first 16-hours period (12:00 am to 04:00 pm UTC 
August 29, 2005) of the numerical simulations (the sloshing motion changes $180^{\circ}$ in 16 hours). In detail, the moving direction of the oscillation of a semi-enclosed water body induced by a hurricane rotates in a clockwise pattern even though a hurricane circulates counterclockwise and the direction of the accompanying wind generated by the hurricane can turn in a counterclockwise pattern.

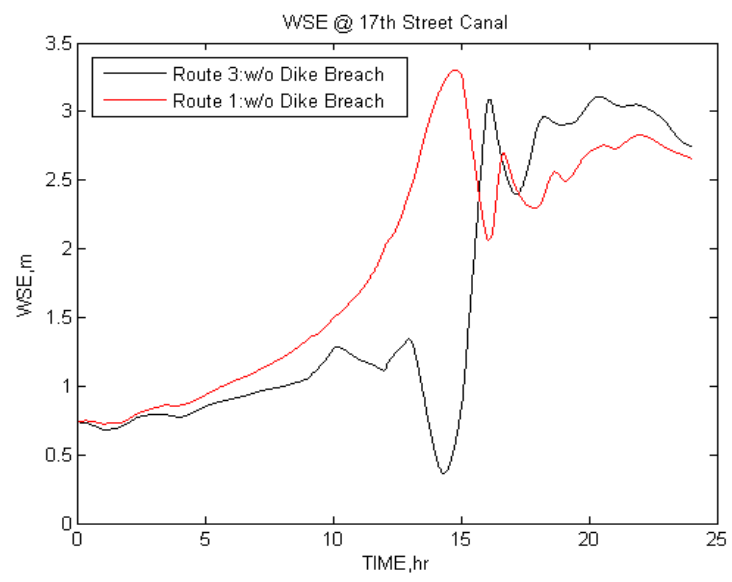

Figure 15. Computed Hydrograph, $17^{\text {th }}$ Street Canal

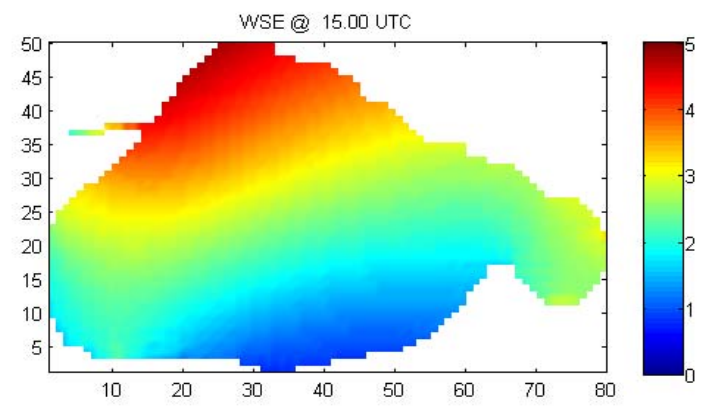

Figure 16. Contours of WSE at 03:00 pm (UTC) August 29, 2005

The computed hydrographs of the water surface elevation (WSE) showing on S-N and W-E crosssections of Lake Pontchartrain induced by the wind generated through the Route 3-traveling Hurricane Katrina are presented in Figures 17 and 18, respectively. It is seen from Figures 17 and 18 that the wind-induced oscillations in Lake Pontchartrain are the apparent phenomena as Hurricane Katrina progressed over the west shore and its surrounding regions of Lake Pontchartrain (Route 3 in Figure 5). 


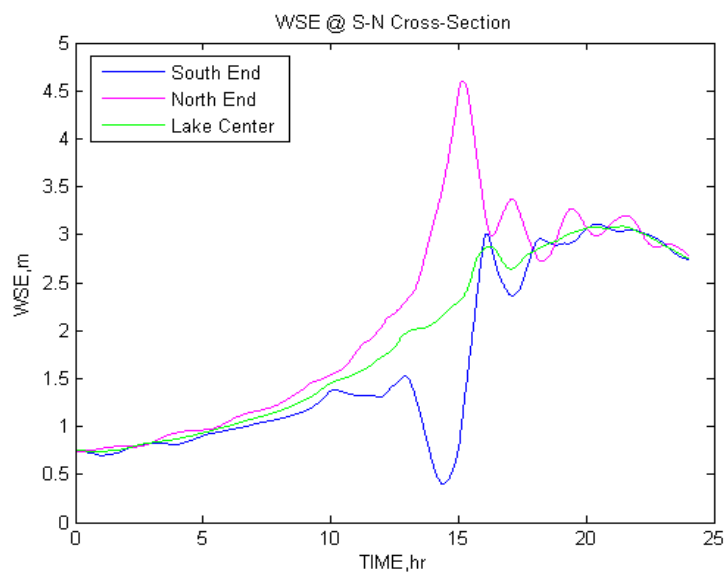

Figure 17. Hydrographs of the S-N cross-section

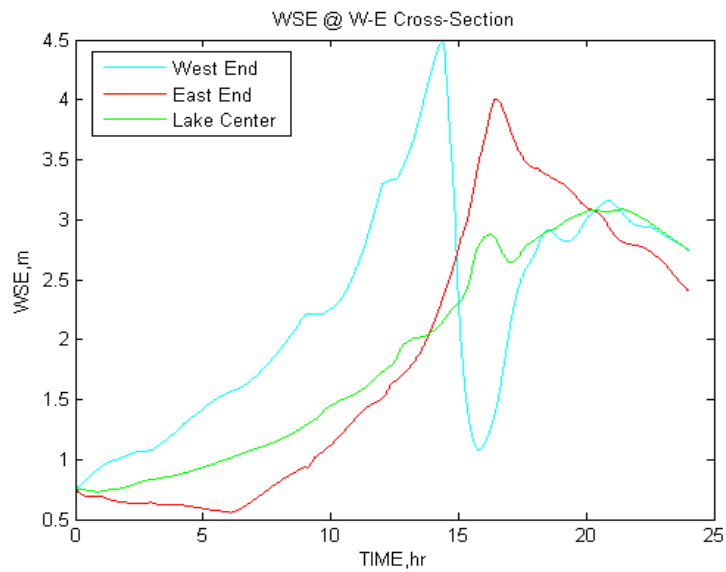

Figure 18. Hydrographs of the W-E cross-section

\section{Hurricane Katrina Traveling With Reduced Forward Speeds}

The computed hydrograph (solid black line) obtained from the present model for the $17^{\text {th }}$ Street Canal is presented in Figure 19. The contour map showing the computed water surface elevation (WSE) for the entire Lake Pontchartrain at the $18^{\text {th }}$ hour is presented in Figure 20.

From Figure 19, it is seen that the peak water surface elevation (WSE) computed by the present model is approximately $4.4449 \mathrm{~m}$ at the $17^{\text {th }}$ Street Canal site. Thus, it is seen that the peak water surface elevation induced by the Route 1-traveling Hurricane Katrina with reduced forward speeds is much larger than the peak water surface level induced by the Route 1-traveling Hurricane Katrina at the $17^{\text {th }}$ Street Canal site (4.4449 m versus $3.3020 \mathrm{~m}$ ) after comparing the computed hydrograph made under the wind generated by the hurricane with the one made under the wind generated by the Route 1traveling Hurricane Katrina (see the solid red line in Figure 19). Therefore, it can be claimed that this significant difference in water surface elevation is caused by a hurricane passing over Lake Pontchartrain with different forward speeds although the strength (pressure and wind speed) of this synthetic hurricane is identical to the original Hurricane Katrina.

Furthermore, the moving direction of the storm surge gradually changes from the west direction to the east direction in a counterclockwise-turning pattern within the entire 24-hours period (12:00 am UTC August 29, 2005 to 12:00 am UTC August 30, 2005) of the numerical simulations (the sloshing motion slowly changes $180^{\circ}$ in 24 hours).

The computed hydrographs of the water surface elevation (WSE) showing on S-N and W-E crosssections of Lake Pontchartrain induced by the wind generated through the Route 1-Traveling Hurricane Katrina with reduced forward speeds are presented in Figures 21 and 22, respectively. It is seen from Figures 21 and 22 that the wind-induced oscillations in Lake Pontchartrain are the evident 
phenomena as the Hurricane Katrina with reduced forward speeds progressed over the Southeast Louisiana region (Route 1 in Figure 5).

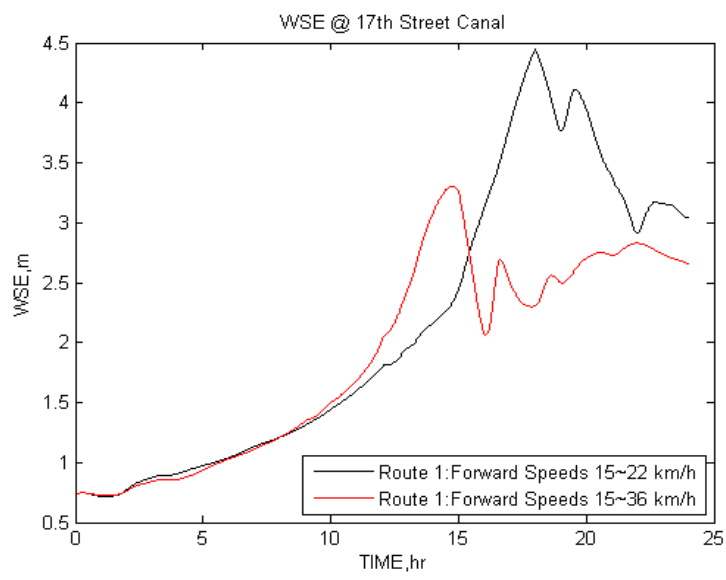

Figure 19. Computed Hydrograph, $17^{\text {th }}$ Street Canal

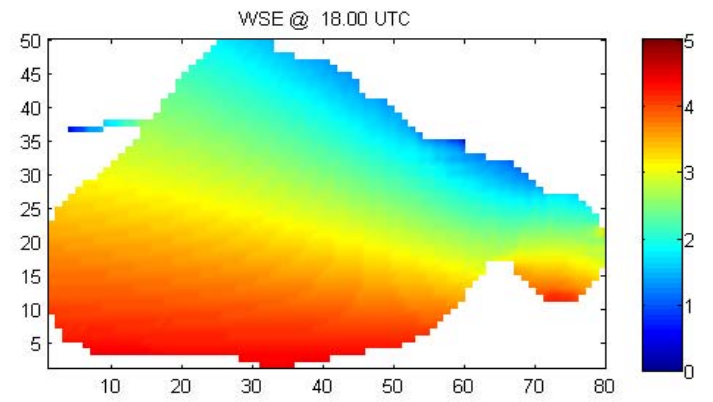

Figure 20. Contours of WSE at 06:00 pm (UTC) August 29, 2005

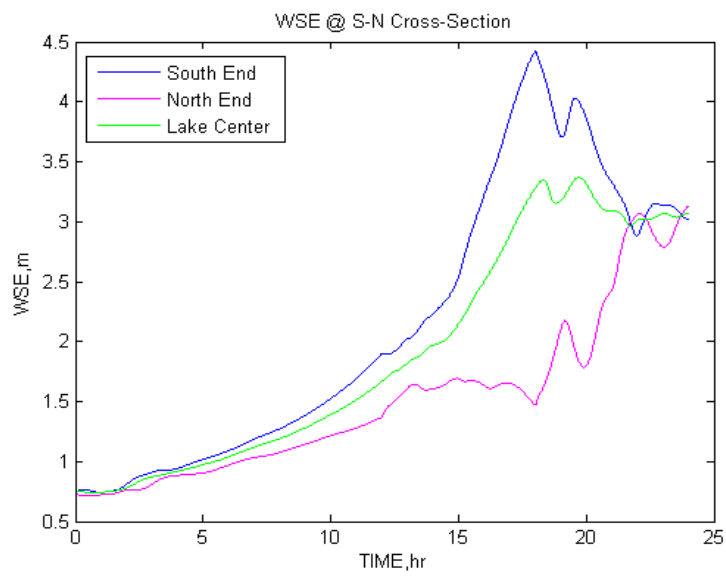

Figure 21. Hydrographs of the S-N cross-section 


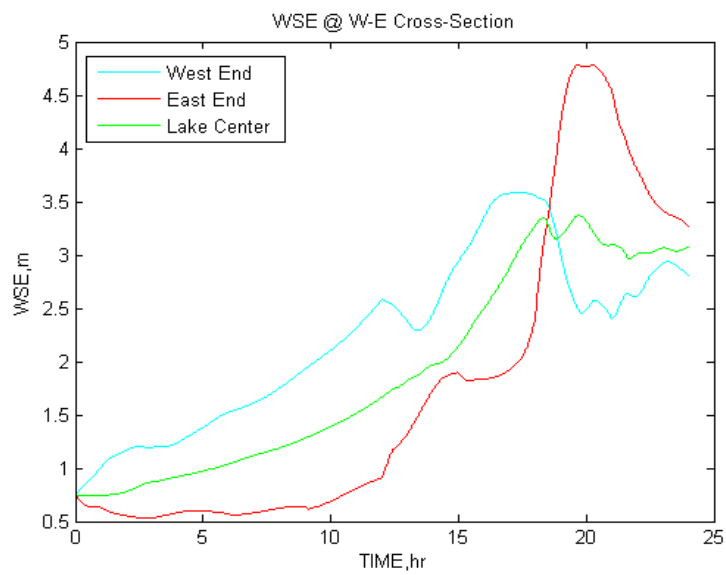

Figure 22. Hydrographs of the W-E cross-section

\section{Risk-Based Design and Analysis}

The potential application of the present model is to assist the design of the water-front structure surrounding the semi-enclosed water body that has been negatively influenced by the oscillations induced by hurricanes. Accompanying with the historical records of the paths and strengths of hurricanes which have brought the catastrophic damages to the surrounding communities of the bays, lakes, and harbors, the oscillation phenomena induced by the hurricanes will be fully understood. Therefore, the numerical simulations generated by the present model can help the planners to determine the optimal size of the hydraulic structures protecting the surrounding communities of the semi-enclosed water body.

The concept of risk-based design and analysis has been known for many years. The basic concept of risk-based design is schematically shown in Figure 23. The risk function accounting for the uncertainties of various factors can be obtained by using the reliability computation procedures. Alternatively, the risk function can account for the potential undesired disaster associated with the failure of hydraulic structures.

As the size of the hydraulic structure increases, the annual installation cost increases while the annual expected damage cost associated with the system failure decreases. The lowest point of the total annual expected cost curve will be used to determine the optimal risk-based design size of the hydraulic structure.

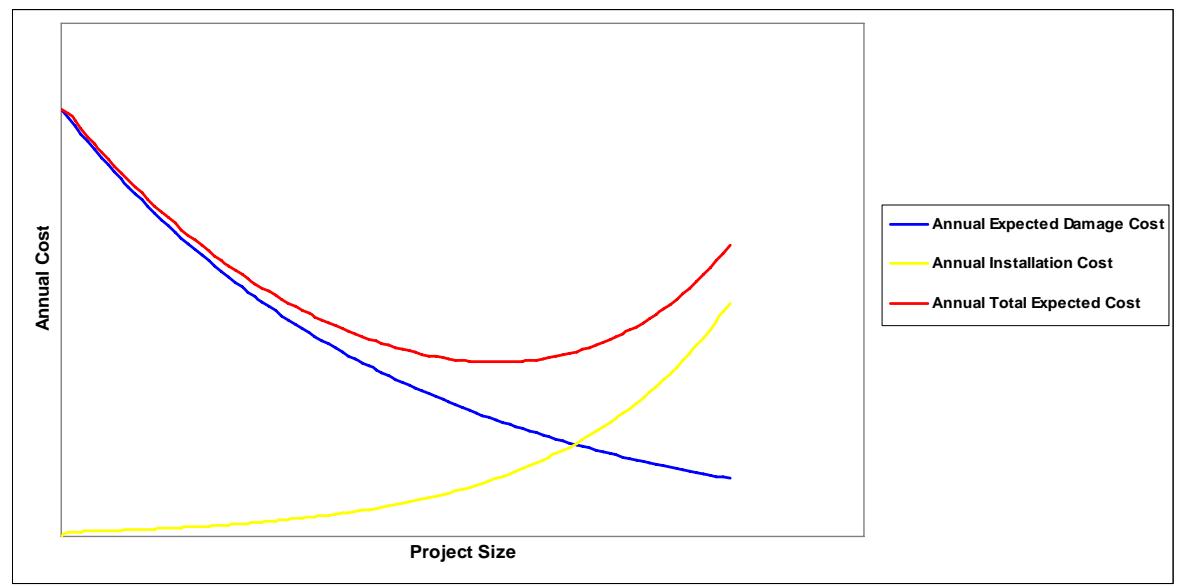

Figure 23. Schematic Diagram of Risk-Based Design

\section{CONCLUSIONS}

The major objective of this research has been to study the oscillations of the semi-enclosed water body induced by hurricanes. A finite-volume method (FVM) model is developed to solve the depth- 
averaged, non-linear shallow-water equations. The present model is used to investigate the oscillations in Lake Pontchartrain induced by wind generated by the four (4) synthetic hurricanes, including Hurricane Katrina, between 00:00 UTC August 29, 2005 and 00:00 UTC August 30, 2005. The available meteorological data of Hurricane Katrina is used to re-generate the hurricane for the present model and the available measured data of the water levels in Lake Pontchartrain is used to verify the simulated water surface elevations (WSE's) obtained from the present model.

Hurricane Katrina moves in a nearly north direction and passes through the regions close to the east shore of Lake Pontchartrain between 12:00 am and 06:00 pm UTC August 29, 2005. Because of these two characteristics of the interaction between the hurricane and the lake, the sloshing motion of the lake water surface rotates in a counterclockwise pattern as the hurricane circulates counterclockwise. The closest encounter between Hurricane Katrina and Lake Pontchartrain takes place between 12:00 and 06:00 pm UTC August 29, 2005. During this 6-hours period, the highest amplitude of oscillation (maximum WSE) along the south shore of the lake happens around 03:00 pm UTC with a magnitude of $3.27 \mathrm{~m}$ to $3.30 \mathrm{~m}$ predicted by the present model while the highest water level, reported in IPET report, associated with the time is within the range of $10.8 \mathrm{ft}$ to $12.0 \mathrm{ft}$ (or 3.29 $\mathrm{m}$ to $3.66 \mathrm{~m}$ ) along the south shore of Lake Pontchartrain. Based on the IPET report, the majority of floods caused by the storm surge induced by Hurricane Katrina in the highly-populated communities along the south shore of Lake Pontchartrain took place within this 6-hours period. Consequently, these floods created the severe human loss and property damages in these communities.

When the eye of Hurricane Katrina is passing through the region along the east shore of Lake Pontchartrain, the highest amplitude (maximum WSE) of oscillation (storm surge) along the south shore of Lake Pontchartrain takes place at the time at which the sloshing motion in the lake is moving toward the south, directly intruding into the region along the south shore of the lake. Consequently, the major floods caused by these gigantic oscillations induced by Hurricane Katrina within a short period of time along the south shore of Lake Pontchartrain create a catastrophe causing enormous impacts to the city of New Orleans even though the city is protected by the hurricane protection systems built under the Lake Pontchartrain and Vicinity project, one of three projects under a comprehensive hurricane protection plan for New Orleans and the Southeast Louisiana region.

The most severe results in the resulting water surface elevations (WSE's) under the four (4) synthetic hurricanes are from the simulation of Hurricane Katrina traveling along its original route with reduced forward speeds. This simulated hurricane moves in a nearly north direction and passes through the regions nearby the east shore of Lake Pontchartrain between 12:00 am UTC August 29, 2005 and 12:00 am UTC August 30, 2005 corresponding to the entire 24-hours of the numerical simulations made by the present model. Because of these two characteristics of the interaction between the hurricane and the lake, the sloshing motion at Lake Pontchartrain rotates in a counterclockwise pattern as the hurricane circulates counterclockwise. The closest encounter between this simulated hurricane and Lake Pontchartrain takes place between 03:00 pm UTC August 29, 2005 and 12:00 am UTC August 30, 2005. During this 9-hours period, the highest amplitude of oscillation (maximum WSE) along the south shore of Lake Pontchartrain would happen around 06:00 pm UTC with a magnitude of $4.33 \mathrm{~m}$ to $4.44 \mathrm{~m}$ predicted by the present model. Evidently, the maximum water surface elevations (WSE's) along the south shore of Lake Pontchartrain induced the wind generated by this synthetic hurricane (Hurricane Katrina traveling on its original route with reduced forward speeds) would be approximately $1 \mathrm{~m}$ higher than the ones induced by the wind generated by the genuine Hurricane Katrina; consequently, the floods and the accompanying catastrophes caused by this synthetic hurricane could even be much worse than the ones caused by Hurricane Katrina.

\section{REFERENCES}

Ferziger, J., Peric, M. 2002. Computational Methods for Fluid Dynamics, $3^{\text {rd }}$ ed.. Springer-Verlag Berlin Heidelberg New York.

Interagency Performance Evaluation Task Force (IPET) 2006. Performance Evaluation of the New Orleans and Southeast Louisiana Hurricane Protection System. U.S. Army Corps of Engineers.

Tan, W. 1992. Shallow Water Hydrodynamics. Elsevier Science Publishers, The Netherlands. Tung, Y. K. 2002. Key Lecture: Risk-Based Design of Flood Defense Systems. Flood Defense 2002, 71-81. 